\title{
Estratégias de desinfecção de Candida albicans e os seus efeitos em resinas acrílicas: Uma revisão integrativa
}

\author{
Strategies for disinfecting Candida albicans and their effects on acrylic resins: An integrative \\ review
}

Estrategias para desinfectar Candida albicans y sus efectos en las resinas acrílicas: Una revisión integrativa

\author{
Isadora Lícia Inácio Silva \\ ORCID: https://orcid.org/0000-0002-6676-8958 \\ Centro Universitário Tabosa de Almeida, Brasil \\ E-mail: isadoraliciainacio@gmail.com \\ Felipe Jhonne Dias Inácio \\ ORCID: https://orcid.org/0000-0001-5260-4007 \\ Centro Universitário Tabosa de Almeida, Brasil \\ E-mail: felipejhonneee@gmail.com \\ Rayane Faustino de Morais \\ ORCID: https://orcid.org/0000-0001-5089-774X \\ Centro Universitário Tabosa de Almeida, Brasil \\ E-mail: raianemorais@ hotmail.com \\ Patricia Lins Azevedo do Nascimento \\ ORCID: https://orcid.org/0000-0002-6335-0193 \\ Centro Universitário Tabosa de Almeida, Brasil \\ E-mail: patricianascimento@asces.edu.br \\ Cláudia Cristina Brainer de Oliveira Mota \\ ORCID: https://orcid.org/0000-0002-7909-5908 \\ Centro Universitário Tabosa de Almeida, Brasil \\ E-mail: claudiabmota@gmail.com
}

\begin{abstract}
Resumo
O objetivo deste estudo foi revisar a eficácia de métodos e uso de produtos sintéticos ou fitoterápicos de controle fúngico e microbiano para materiais à base de resina acrílica e seus impactos na longevidade das próteses dentárias. Foi realizado um levantamento bibliográfico nas bases de dados PubMed e SciELO, com o cruzamento de descritores, e filtros de restrição ao período de publicação e idioma. Após a remoção dos artigos duplicados, a seleção dos estudos foi realizada em duas etapas: leitura de título, seguida pela leitura dos resumos. Os estudos que foram selecionados passaram por leitura completa e seus dados relevantes foram inseridos em dois quadros padronizados para análise e discussão de dados. Dos 501 artigos selecionados, apenas 33 se enquadraram nos critérios de inclusão, sendo 27 estudos laboratoriais, 4 ensaios clínicos e 2 clínico-laboratoriais. A utilização de métodos para desinfecção de forma química ou alternativa, como aquecimento em energia de micro-ondas e imersão em hipoclorito de sódio promovem uma desinfecção adequada, porém com alterações significativas na resina acrílica. Logo, estratégias de controle microbiano com o uso de fitoterápicos e nanomateriais para inclusão na resina acrílica vem sendo amplamente estudados. A desinfecção de próteses de forma química é uma prática essencial para o controle microbiano, e diversos materiais estão dispostos para este fim.
\end{abstract}

Palavras-chave: Resinas acrílicas; Desinfecção; Prótese dentária; Polimetil metacrilato; Candida.

\begin{abstract}
This study aimed to review the efficacy of methods and use of synthetic or phytotherapeutic products for fungal and microbial control, for materials based on acrylic resin and their impact on the longevity of the dental prosthesis. A bibliographic survey was carried out in PubMed and SciELO databases, using and crossing of Keywords, with restriction filters to the period of publication and language. After removing duplicate articles, the selection of studies was carried out in two stages: reading the title, followed by reading the abstracts. The studies that were selected went through a complete reading and their relevant data were inserted in two standardized tables for data analysis and discussion. 501 articles were select, only 33 of them presented all inclusion criteria, 27 which were laboratory studies, 4 clinical trials, and 2 clinical-laboratory studies. The use of methods for chemical or alternative disinfection, such as heating in microwave energy and immersion in sodium hypochlorite, promote adequate disinfection, but there are significant changes in acrylic resin. Therefore, microbial control strategies using herbal medicines and nanomaterials
\end{abstract}


for inclusion in acrylic resin have been widely studied. Chemical disinfection of dentures is an essential practice for microbial control, and several materials are available for this purpose.

Keywords: Acrylic resins; Disinfection; Dental prosthesis; Polymethyl methacrylate; Candida.

\section{Resumen}

Este estudio tuvo como objetivo revisar la eficacia de métodos y uso de productos sintéticos o fito terapéuticos para el control de hongos y microbios, para materiales basados en resina acrílica y su impacto en la longevidad de la prótesis dental. Se realizó un levantamiento bibliográfico en las bases de datos PubMed y SciELO, utilizando y cruzando palabras llaves, con filtros de restricción al período de publicación e idioma. Después de eliminar los artículos duplicados, la selección de los estudios se realizó en dos etapas: lectura del título, seguida de lectura de los resúmenes. Los estudios seleccionados pasaron por una lectura completa y sus datos relevantes se insertaron en dos tablas estandarizadas para el análisis y discusión de los datos. Se seleccionaron 501 artículos, solo 33 de ellos presentaron todos los criterios de inclusión, 27 que fueron estudios de laboratorio, 4 ensayos clínicos y 2 clínico-laboratorio. El uso de métodos de desinfección química o alternativa, como el calentamiento en energía de microondas y la inmersión en hipoclorito de sodio, promueven una desinfección adecuada, pero hay cambios significativos en la resina acrílica. Por tanto, se han estudiado ampliamente las estrategias de control microbiano que utilizan a base de hierbas y nanomateriales para su inclusión en resina acrílica. La desinfección química de las dentaduras postizas es una práctica esencial para el control microbiano y hay varios materiales disponibles para este propósito.

Palabras clave: Resinas acrílicas; Desinfección; Prótesis dental; Polimetil metacrilato; Candida.

\section{Introdução}

As perdas dentárias causam um desequilíbrio nas relações oclusais entre os dentes remanescentes, causando discrepâncias na realização das funções estomatognáticas (Batista, Lawrence, \& Sousa, 2015). No edentulismo total ou parcial a reabilitação pode ser realizada pelo uso de próteses dentárias devolvendo a forma, função e estética dos elementos dentários perdidos (Batista, Lawrence, \& Sousa, 2017).

As resinas acrílicas de polimetil metacrilato (PMMA) são os principais materiais utilizados na confecção dessas próteses, visto que reúnem características como biocompatibilidade, estabilidade dimensional, boa capacidade de polimento, assim preenchendo grande parte dos requisitos estéticos e funcionais (Camacho, Svidzinski, Furlaneto, Lopes, \& Correa, 2014).

Entretanto, o uso de próteses removíveis, principalmente superiores, requer uma atenção especial, visto que altera o ecossistema microbiológico da cavidade oral, proporcionando um ambiente com baixa concentração de oxigênio, redução do fluxo salivar local e favorecimento da colonização de microrganismos, que possuem capacidade de se aderir às superfícies da cavidade oral e dos biomateriais presentes, formando biofilme. Esses são agravados quando as próteses estão mal adaptadas ou a higiene bucal está precária (Sugio et al., 2020; Bastos, Mesquita, Ottoboni, \& Figueiredo, 2015).

A candidose oral é uma infecção oportunista, desencadeada pelo crescimento exacerbado e consequente penetração nos tecidos orais de Candida spp., principalmente a Candida albicans. Quando este microrganismo patogênico está associado aos pacientes que fazem uso de prótese removível, instala-se um quadro de estomatite protética associada à Candida, que representa o quadro mais frequente de candidose oral, sendo responsável por aproximadamente $70 \%$ dos casos de infecção (Simões, Fonseca, \& Figueiral, 2013).

O diagnóstico da estomatite por Candida é realizado através da análise do quadro clínico associado os resultados de exames laboratoriais, os quais incluem a citopatologia e a cultura microbiológica (Leite, Piva, \& Martins Filho, 2015).

Geralmente a terapêutica de eleição consiste na combinação de antifúngico em contato direto com a superfície da resina acrílica da prótese e a mucosa do paciente, com uso de substâncias desinfetantes para a redução da infecção (Sesma \& Morimoto, 2011). Em contrapartida, estratégias alternativas de inclusão de nanobiomateriais com potencial antimicrobiano à base de PMMA e uso fitoterápicos vem sendo considerados como agentes de controle biológico da formação de biofilmes patogênicos na superfície das próteses (Castro et al., 2014; Salles et al., 2015).

Dentre as propriedades das resinas acrílicas utilizadas para a confecção de bases de próteses à base de PMMA, 
aquelas relacionadas com a superfície, como a rugosidade, microdureza, tensão superficial e cor são de grande importância, visto que em âmbito clínico, suas falhas podem levar ao aparecimento de manchamento da prótese e aderência e retenção de biofilme patogênico, como de C. albicans (Fernandes, 2009).

Durante a vida útil da prótese é propício que exista uma alteração da propriedade de cor, principalmente pela ação de absorver líquidos, como desinfetantes químicos e substâncias corantes. A exposição excessiva e contínua, a esses líquidos podem promover alterações na textura superficial e de cor, em decorrência da sorção de líquidos no interior do polímero ou deposição superficial (Barbosa, Montenegro \& Duarte, 2013; Fernandes, 2009).

Este presente estudo propõe revisar os métodos de controle fúngico e microbiano para materiais à base de resina acrílica e seus impactos na durabilidade das próteses dentárias expostas a esses diferentes métodos de tratamento. Além disso, promove uma discussão sobre a efetividade dos métodos de prevenção e tratamento antifúngico com substâncias sintetizadas artificialmente ou fitoterápicos.

\section{Metodologia}

Foi realizada uma revisão integrativa da literatura, por meio de consulta às bases de dados PubMed e SciELO. Para fins de buscas avançadas, foram realizados os cruzamentos de descritores segundo o MeSH (Medical Subject Headings), com o auxílio do operador booleano AND, sendo eles: Acrylic resins / Resinas acrílicas; Disinfection / Desinfecção; Dental Prosthesis / Prótese dentária; Polymethyl methacrylate / Polimetil metacrilato; Candida. Os critérios de inclusão utilizados foram: ensaios clínicos e/ou laboratoriais publicados na íntegra, nos idiomas português e inglês, com data de publicação entre os anos 2010 e 2020, que abordassem os métodos de controle fúngico/microbiano para materiais à base de resina acrílica e seus impactos sobre a superfície e durabilidade das próteses dentárias.

A seleção dos estudos foi realizada inicialmente utilizando filtros para localização de artigos e estudos científicos publicados em inglês e português, disponíveis em texto completo entre os anos de 2010 e 2020. Em seguida os artigos duplicados foram removidos e a seleção seguiu em duas fases: na primeira fase, foram selecionados os estudos por meio da leitura dos títulos; posteriormente, na segunda fase, ocorreu a seleção dos artigos por meio da leitura dos resumos. Nesse momento todos os resumos foram lidos por dois revisores, sem que houvesse comunicação entre si. Nas situações em que não houve concordância quanto à inclusão ou não de algum artigo, um terceiro revisor interveio na seleção. Dessa forma, os estudos selecionados que se encaixavam nos critérios de inclusão, seguiram para leitura na íntegra.

Após a leitura completa, os artigos que apresentavam o objetivo da pesquisa foram incluídos para a extração de dados, acerca de informações relevantes sobre os estudos, como: o tipo de resina utilizado, técnicas de desinfecção, testes e resultados encontrados, a ser inseridos em dois quadros padronizados para melhor análise e discussão dos resultados encontrados. Esta metodologia seguiu as recomendações PRISMA. A Figura 1 apresenta um fluxograma da estratégia metodológica de revisão utilizada. 
Figura 1 - Fluxograma de estratégia de busca nas bases de dados.

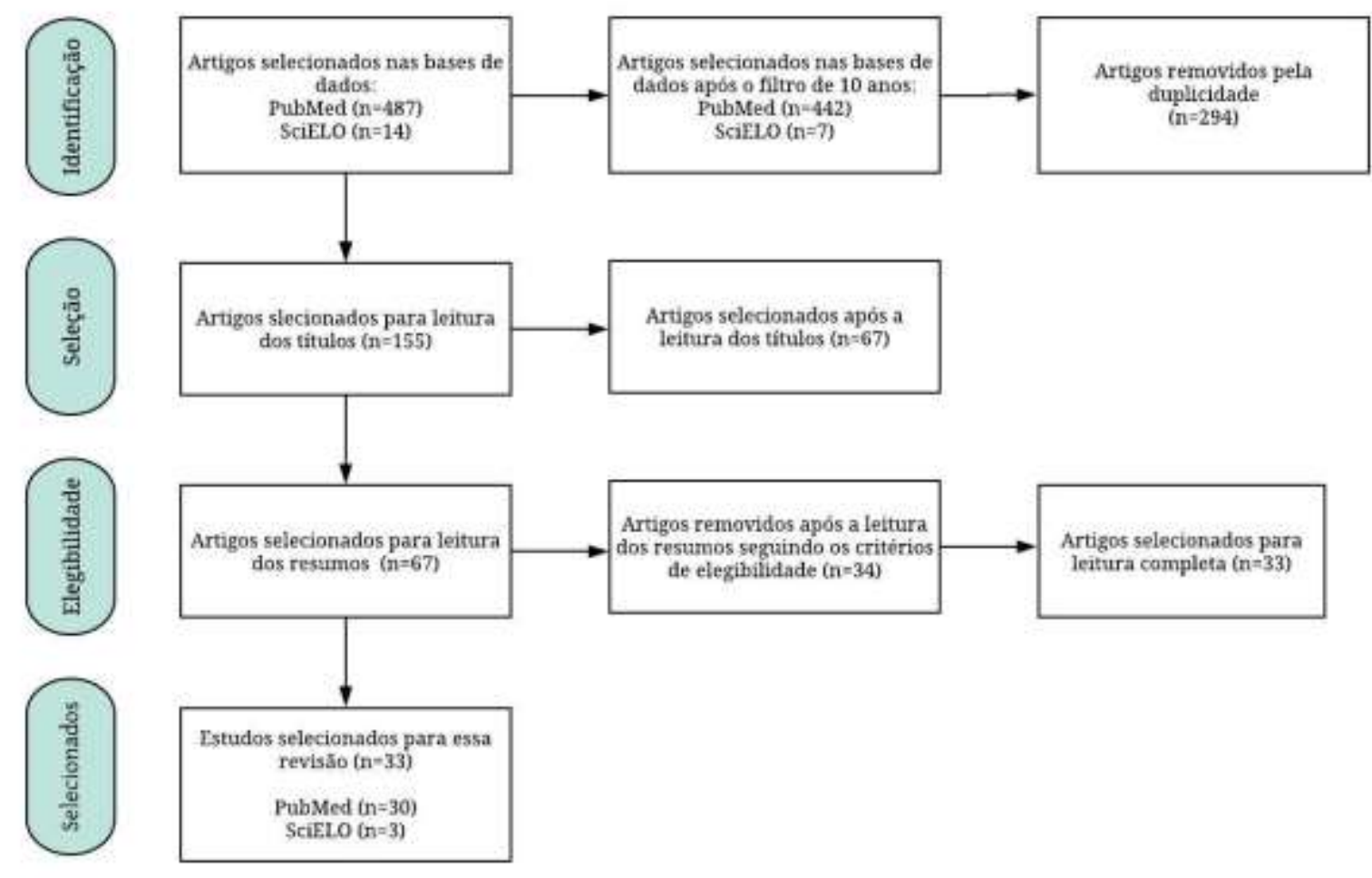

Fonte: Autores.

\section{Resultados}

O levantamento executado na pesquisa eletrônica com o cruzamento dos descritores nas bases de dados PubMed e SciELO resultou em 501 artigos. Após aplicar o filtro de 10 anos, restaram 449 artigos, dos quais foram removidas 294 duplicatas, resultando em 155 artigos para leitura dos títulos, que representa a primeira fase de seleção. Após a leitura dos títulos, 67 artigos seguiram para a segunda etapa da seleção com a leitura dos resumos, que selecionou 33 estudos para leitura completa, apresentados nos Quadros 1 e 2.

Dentre os 33 estudos selecionados, apresentados nos Quadros 1 e 2, 27 foram estudos laboratoriais, 4 ensaios clínicos e 2 clínico-laboratoriais. Destes, apenas dois estudos não fizeram menção à quantidade de amostras e dois não citaram o tipo de resina acrílica utilizada no estudo.

Os métodos de controle de biofilme de C. albicans no processo de desinfecção da prótese mais utilizados nos estudos foram: imersão em soluções disponíveis comercialmente e acessíveis à maioria dos pacientes, como clorexidina e hipoclorito de sódio (HS); imersão em soluções fitoterápicas; exposição à luz ultravioleta; aquecimento em micro-ondas; inclusão de materiais antimicrobianos na resina de base de prótese (Hashizume, Hoscharuk, \& Moreira, 2015; Fortes et al., 2015; YildirimBicer, Peker, Akca, \& Celik, 2014; Fouda et al., 2019).

Para avaliar a eficácia do método de desinfecção, testes de potencial antimicrobiano e quantificação de biofilme foram realizados, assim como testes para analisar o impacto dessas substâncias e materiais na superfície e estrutura das resinas acrílicas, como rugosidade superficial, microdureza, estabilidade de cor, resistência flexural, módulo flexural, estabilidade dimensional, dentre outros (Nirale, Thombre, \& Kubasad, 2012; Kamonkhantikul, Arksornnukit, \& Takahashi, 2017; Tripathi, Phukela, Yadav, \& Malhotra, 2018). 
Quadro 1 - Características dos estudos laboratoriais incluídos.

\begin{tabular}{|c|c|c|c|c|}
\hline Autor/ano & Tipo de resina acrílica & Tipo de desinfecção & $\begin{array}{c}\text { Testes } \\
\text { realizados }\end{array}$ & Resultados \\
\hline $\begin{array}{l}\text { Castro et al. } \\
(2014)\end{array}$ & Autopolimerizável & $\begin{array}{l}\text { Inclusão de vanadato de } \\
\text { prata nanoestruturado }(\beta- \\
\left.\mathrm{AgVO}_{3}\right) \text { a } 0,5 \%, 1 \%, 2,5 \%, \\
5 \% \text { e } 10 \% \text { na resina acrílica. } \\
\text { n= não especifica a } \\
\text { quantidade }\end{array}$ & $\begin{array}{l}\text { Potencial } \\
\text { antimicrobiano, } \\
\text { dureza } \\
\text { superficial e } \\
\text { resistência à } \\
\text { compressão }\end{array}$ & $\begin{array}{l}\text { A inclusão de } \beta-\mathrm{AgVO}_{3} \text { na resina acrílica teve } \\
\text { potencial antimicrobiano contra todas as cepas } \\
\text { testadas. Além disso, a adição de } 0,5 \% \text { do } \\
\text { nanomaterial pode aumentar a dureza } \\
\text { superficial e a resistência à compressão. As } \\
\text { taxas mais altas do nanomaterial não } \\
\text { promoveram mudanças nas propriedades da } \\
\text { resina em comparação com os grupos que não } \\
\text { receberam a inclusão. }\end{array}$ \\
\hline $\begin{array}{l}\text { Hashizume, } \\
\text { Hoscharuk, } \\
\& \quad \text { Moreira } \\
(2015)\end{array}$ & Termopolimerizável & $\begin{array}{l}\text { Imersão em clorexidina a } \\
2 \% \text {, hipoclorito de sódio a } \\
1 \% \text {, vinagre e peróxido de } \\
\text { hidrogênio } 10 \mathrm{v} \text {. } \\
\mathbf{n}=\mathbf{1 5} \text { por grupo }\end{array}$ & $\begin{array}{l}\text { Potencial } \\
\text { antimicrobiano }\end{array}$ & $\begin{array}{l}\text { A imersão em clorexidina a } 2 \% \text { e hipoclorito de } \\
\text { sódio a } 1 \% \text { promoveram a redução máxima de } \\
\text { Candida albicans aderida à resina acrílica. O } \\
\text { vinagre apresentou potencial antifúngico } \\
\text { intermediário, sendo considerado uma } \\
\text { alternativa viável e de baixo custo para a } \\
\text { desinfecção de próteses, o peróxido de } \\
\text { hidrogênio } 10 \mathrm{v} \text { propiciou um efeito inferior em } \\
\text { comparação com às demais soluções. }\end{array}$ \\
\hline $\begin{array}{l}\text { Fortes et al. } \\
\text { (2015) }\end{array}$ & $\begin{array}{l}\text { Termopolimerizável } \\
\text { autopolimerizável e } \\
\text { termopolimerizável por } \\
\text { micro-ondas }\end{array}$ & $\begin{array}{l}\text { Aquecimento em energia de } \\
\text { micro-ondas } 840 \quad \mathrm{~W} \text { e } \\
\text { imersão em ácido } \\
\text { peracético } 0,2 \% . \\
\text { n= } 15 \text { por grupo } \\
\end{array}$ & $\begin{array}{l}\text { Potencial } \\
\text { antimicrobiano }\end{array}$ & $\begin{array}{l}\text { A imersão em ácido peracético a } 0,2 \% \text { por } 5 \\
\text { minutos, assim como a irradiação de micro- } \\
\text { ondas } 840 \mathrm{~W} \text { por } 1 \text { minuto foram eficientes } \\
\text { para desinfecção dos três tipos de resinas } \\
\text { acrílicas. }\end{array}$ \\
\hline $\begin{array}{l}\text { Martins, \& } \\
\text { Moretti } \\
\text { Neto (2017) }\end{array}$ & $\begin{array}{l}\text { Termopolimerizável e } \\
\text { autopolimerizável }\end{array}$ & $\begin{array}{l}\text { Imersão em clorexidina a } \\
0,12 \% \text {, hipoclorito de sódio } \\
\text { a } 1 \% \text { e solução de Corega } \\
\text { Tabs (GSK). } \\
\mathbf{n = 1 5} \text { por grupo }\end{array}$ & $\begin{array}{l}\text { Microdureza } \\
\text { superficial }\end{array}$ & $\begin{array}{l}\text { As amostras de resinas que passaram pelos } \\
\text { ciclos de desinfecção nas soluções de } \\
\text { clorexidina a } 0,12 \% \text { e Corega Tabs } \\
\text { apresentaram redução de microdureza } \\
\text { superficial. A imersão na solução de hipoclorito } \\
\text { de sódio a } 1 \% \text { não reduziu a microdureza, } \\
\text { promovendo menores danos à estrutura das } \\
\text { próteses. }\end{array}$ \\
\hline $\begin{array}{l}\text { Yildirim- } \\
\text { Bicer, } \\
\text { Peker, } \\
\text { Akca, \& } \\
\text { Celik } \\
(2014)\end{array}$ & $\begin{array}{l}\text { Termopolimerizável e } \\
\text { Autopolimerizável }\end{array}$ & $\begin{array}{l}\text { Imersão em hipoclorito de } \\
\text { sódio a } 1 \% \text {, enxaguatório } \\
\text { bucal contendo própolis } \\
\text { (MCP), solução de Corega } \\
\text { Tabs (GSK), vinagre branco } \\
\text { a } 50 \% \text { e } 100 \% \text {, } \\
\text { aquecimento em energia de } \\
\text { micro-ondas } 650 \mathrm{~W} \text { e } \\
\text { exposição à luz ultravioleta. } \\
\mathbf{n = 2 0} \text { por grupo }\end{array}$ & $\begin{array}{l}\text { Potencial } \\
\text { antimicrobiano }\end{array}$ & $\begin{array}{l}\text { O vinagre branco a } 100 \% \text { foi a solução que se } \\
\text { mostrou mais eficaz no controle de Candida } \\
\text { albicans, seguido do vinagre branco a } 50 \% \text {, } \\
\text { Corega Tabs, energia de micro-ondas, } \\
\text { hipoclorito de sódio a } 1 \% \text {, luz ultravioleta e } \\
\text { como o menos eficaz, o enxaguatório bucal } \\
\text { contendo própolis para as amostras de resina } \\
\text { autopolimerizável. Nas amostras de resina } \\
\text { termopolimerizável, o vinagre } 100 \% \text { também } \\
\text { foi o mais eficiente, seguido do hipoclorito de } \\
\text { sódio a } 1 \% \text {, energia de micro-ondas, vinagre } \\
50 \% \text {, Corega Tabs, ultravioleta e enxaguatório } \\
\text { bucal contendo própolis. }\end{array}$ \\
\hline $\begin{array}{l}\text { Castro et al. } \\
(2015)\end{array}$ & Autopolimerizável & $\begin{array}{l}\text { Imersão em vinagre de } \\
\text { álcool }(0,04 \mathrm{~g} / \mathrm{ml} \text { de ácido } \\
\text { acético }) \text { e nistatina. } \\
\mathbf{n = 1 0} \text { por grupo para } \\
\text { análise de cor } \\
\mathbf{n = 6} \text { por grupo para } \\
\text { análise microbiana }\end{array}$ & $\begin{array}{l}\text { Potencial } \\
\text { antimicrobiano, } \\
\text { rugosidade } \\
\text { superficial e } \\
\text { estabilidade de } \\
\text { cor }\end{array}$ & $\begin{array}{l}\text { O vinagre de álcool apresentou efeito fungicida } \\
\text { a partir de } 120 \text { minutos de imersão, diferindo da } \\
\text { nistatina que apresentou efeito fungistático. O } \\
\text { vinagre não promoveu nenhuma alteração de } \\
\text { cor e rugosidade de superfície das amostras. }\end{array}$ \\
\hline $\begin{array}{l}\text { Zoccolotti } \\
\text { et al. }(2018)\end{array}$ & Termopolimerizável & $\begin{array}{l}\text { Imersão em solução de } \\
\text { Dettol (Reckitt Benckiser), } \\
\text { solução de Protex (Colgate- } \\
\text { Palmolive) e solução de } \\
\text { Lifebuoy (Unilever). } \\
\text { n= não informado }\end{array}$ & $\begin{array}{l}\text { Potencial } \\
\text { antimicrobiano, } \\
\text { citotoxicidade, } \\
\text { estabilidade de } \\
\text { cor, rugosidade } \\
\text { superficial e } \\
\text { dureza } \\
\text { superficial } \\
\end{array}$ & $\begin{array}{l}\text { Nenhum grupo experimental promoveu } \\
\text { citotoxicidade e todos foram eficazes na } \\
\text { redução do biofilme de C. albicans após } 8 \\
\text { horas de imersão, porém Dettol e Lifebuoy } \\
\text { eliminaram de forma total o biofilme formado. } \\
\text { Não houve aumento de rugosidade de superfície } \\
\text { em nenhum grupo. O Lifebuoy promoveu } \\
\text { alterações de cor e dureza das amostras. }\end{array}$ \\
\hline $\begin{array}{l}\text { Maluf et al. } \\
(2020)\end{array}$ & Autopolimerizável & $\begin{array}{l}\text { Inclusão de diacetato de } \\
\text { clorexidina a } 0,5 \%, 1,0 \% \text { e } \\
2,0 \% \text { na resina acrílica. }\end{array}$ & $\begin{array}{l}\text { Potencial } \\
\text { antimicrobiano, } \\
\text { sorção de água e }\end{array}$ & $\begin{array}{l}\text { O diacetato de clorexidina incorporado nas } \\
\text { resinas acrílicas permitiu a inibição do } \\
\text { crescimento de Candida albicans, nas três }\end{array}$ \\
\hline
\end{tabular}




\begin{tabular}{|c|c|c|c|c|}
\hline & & $\mathrm{n}=25$ por grupo & $\begin{array}{ll}\text { grau } & \text { de } \\
\text { conversão } & \end{array}$ & $\begin{array}{l}\text { concentrações testadas e não alterou o grau de } \\
\text { conversão e liberação de monômero residual. } \\
\text { Entretanto, a sorção de água aumentou } \\
\text { significativamente nas concentrações de } 1,0 \% \text { e } \\
2,0 \% \text {. }\end{array}$ \\
\hline $\begin{array}{l}\text { Sczepanski } \\
\text { et al. }(2014)\end{array}$ & Termopolimerizável & $\begin{array}{l}\text { Imersão em hipoclorito de } \\
\text { sódio a } 1 \% \text { e ácido } \\
\text { peracético a } 1 \% \text {. } \\
\mathbf{n = 1 0} \text { por grupo }\end{array}$ & $\begin{array}{l}\text { Rugosidade } \\
\text { superficial } \\
\text { colorimetria }\end{array}$ & $\begin{array}{l}\text { Os desinfetantes não afetam a colorimetria e a } \\
\text { rugosidade da superfície das amostras. }\end{array}$ \\
\hline $\begin{array}{l}\text { Machado, } \\
\text { Giampaolo, } \\
\text { Vergani, } \\
\text { Souza, \& } \\
\text { Jorge } \\
\text { (2011) }\end{array}$ & $\begin{array}{l}\text { Termopolimerizável, } \\
\text { autopolimerizável rígida } \\
\text { e autopolimerizável } \\
\text { resiliente }\end{array}$ & $\begin{array}{l}\text { Imersão em solução de } \\
\text { perborato de sódio a } 3,8 \% \text { e } \\
\text { aquecimento em energia de } \\
\text { micro-ondas } 650 \mathrm{~W} . \\
\mathbf{n = 1 0} \text { por grupo }\end{array}$ & $\begin{array}{l}\text { Rugosidade } \\
\text { superficial }\end{array}$ & $\begin{array}{l}\text { A rugosidade de superfície das amostras } \\
\text { autopolimerizáveis rígidas foi afetada pela } \\
\text { desinfecção por micro-ondas e imersão em } \\
\text { perborato de sódio. Ainda, a desinfecção por } \\
\text { micro-ondas aumentou a rugosidade nas } \\
\text { amostras da resina autopolimerizável resiliente. } \\
\text { Não houve diferenças significativas na } \\
\text { rugosidade de superfície das amostras } \\
\text { termopolimerizáveis. }\end{array}$ \\
\hline $\begin{array}{l}\text { Jafari, Tafti, } \\
\text { Hoseiny, \& } \\
\text { Kazemi } \\
(2015)\end{array}$ & Termopolimerizável & $\begin{array}{l}\text { Imersão em essência de } \\
\text { Zataria multiflora com } \\
\text { concentrações de } 3.125 \text {, } \\
6.25,12.5,50 \text { e } 25 \mathrm{mg} / \mathrm{mL} \text {, } \\
\text { e nistatina. } \\
\mathbf{n = 2 0} \text { por grupo }\end{array}$ & $\begin{array}{l}\text { Potencial } \\
\text { antimicrobiano }\end{array}$ & $\begin{array}{l}\text { As concentrações } 25 \text { e } 50 \mathrm{mg} / \mathrm{mL} \text { da essência } \\
\text { de Zataria possuem potencial antimicrobiano } \\
\text { para remoção total do biofilme de } C \text {. albicans } \\
\text { das superfícies das amostras, semelhante à } \\
\text { eficácia da nistatina. A concentração de } 12,5 \\
\mathrm{mg} / \mathrm{mL} \text { removeu cerca de } 90 \% \text { do biofilme, no } \\
\text { entanto as concentrações de } 3,125 \text { e } 6,25 \\
\mathrm{mg} / \mathrm{mL} \text { mostraram resultado inferior às demais. }\end{array}$ \\
\hline $\begin{array}{l}\text { Al-Saadi } \\
(2014)\end{array}$ & Termopolimerizável & $\begin{array}{l}\text { Aquecimento em energia de } \\
\text { micro-ondas } 900 \mathrm{~W} \text {, } \\
\text { imersão em hipoclorito de } \\
\text { sódio } 5,25 \% \text {, solução de } \\
\text { sabonete Clorox (Clorox), } \\
\text { clorexidina } 0,12 \% \text { e solução } \\
\text { de pastilha higienizadora } \\
\text { BonyPlus (Bonyf AG). } \\
\mathbf{n = 1 2} \text { por grupo }\end{array}$ & $\begin{array}{l}\text { Potencial } \\
\text { antimicrobiano } \\
\text { e estabilidade } \\
\text { dimensional }\end{array}$ & $\begin{array}{l}\text { A desinfecção pela energia de micro-ondas em } \\
\text { ambas potências e hipoclorito de sódio a } 5,25 \% \\
\text { promoveram a redução de } C \text {. albicans sob a } \\
\text { superfície das resinas, enquanto o Clorox, } \\
\text { clorexidina, BonyPlus, não atingiram redução } \\
\text { eficiente. A estabilidade dimensional das } \\
\text { amostras foi alterada quando submetidas a } \\
\text { energia de micro-ondas em potência máxima. }\end{array}$ \\
\hline $\begin{array}{l}\text { Madeira et } \\
\text { al. }(2016)\end{array}$ & Termopolimerizável & $\begin{array}{l}\text { Imersão em Cymbopogon } \\
\text { citratus (Extrato de capim- } \\
\text { limão). } \\
\mathbf{n = 9} \text { por grupo }\end{array}$ & $\begin{array}{l}\text { Potencial } \\
\text { antimicrobiano } \\
\mathrm{e} \quad \text { rugosidade } \\
\text { superficial } \\
\text { Estabilidade de } \\
\text { cor, resistência } \\
\text { flexural } \\
\text { viabilidade } \\
\text { celular }\end{array}$ & $\begin{array}{l}\text { O extrato de capim-limão foi eficaz na redução } \\
\text { de biofilme de Candida albicans, sem provocar } \\
\text { nenhuma alteração de cor, rugosidade e } \\
\text { resistência à flexão. O teste de viabilidade } \\
\text { celular mostrou que o extrato é eficaz e seguro } \\
\text { para células humanas. }\end{array}$ \\
\hline $\begin{array}{l}\text { Polychrona } \\
\text { kis, } \\
\text { Yannikakis, } \\
\& \quad \text { Zissis } \\
(2014)\end{array}$ & Termopolimerizável & $\begin{array}{l}\text { Aquecimento em energia de } \\
\text { micro-ondas com } \\
\text { desinfecção úmida e } \\
\text { desinfecção a seco. } \\
\text { n=6 por grupo }\end{array}$ & $\begin{array}{l}\text { Estabilidade } \\
\text { dimensional }\end{array}$ & $\begin{array}{l}\text { A desinfecção com energia de micro-ondas } \\
\text { promoveu redução dimensional das próteses. } \\
\text { As próteses submetidas a desinfecção úmida } \\
\text { apresentaram maior redução dimensional, } \\
\text { portanto a desinfecção a seco é preferível, visto } \\
\text { que as alterações dimensionais que } \\
\text { promoveram são insignificantes no âmbito } \\
\text { clínico. }\end{array}$ \\
\hline $\begin{array}{l}\text { Ariamanesh } \\
\text { et al. (2019) }\end{array}$ & Termopolimerizável & $\begin{array}{l}\text { Imersão em extrato } \\
\text { alcoólico de Nigella sativa } \\
\text { (cominho preto) com } \\
\text { concentrações de } 0,2,0,4, \\
20 \text { e } 200 \mathrm{mg} / \mathrm{ml} \text {, e nistatina. } \\
\mathbf{n}=\mathbf{5} \text { por grupo }\end{array}$ & $\begin{array}{l}\text { Potencial } \\
\text { antimicrobiano }\end{array}$ & $\begin{array}{l}\text { As concentrações de } 0,2 \text { e } 0,4 \mathrm{mg} / \mathrm{ml} \text { de extrato } \\
\text { de Nigella Sativa não promoveram redução } \\
\text { significativa do biofilme de C. albicans. Os } \\
\text { testes com as concentrações de } 20 \text { e } 200 \mathrm{mg} / \mathrm{ml} \\
\text { reduziram o número de colônias, no entanto } \\
\text { com potencial antimicrobiano inferior à } \\
\text { nistatina. }\end{array}$ \\
\hline $\begin{array}{l}\text { Fouda et al. } \\
(2019)\end{array}$ & Termopolimerizável & $\begin{array}{l}\text { Inclusão de nanodiamante } \\
\text { em concentrações } 0,5 \% \text {, } \\
1 \%, 1,5 \% \text { na resina acrílica. } \\
\mathbf{n = 3 0} \text { por grupo }\end{array}$ & $\begin{array}{l}\text { Potencial } \\
\text { antimicrobiano, } \\
\text { rugosidade } \\
\text { superficial e } \\
\text { ângulo de } \\
\text { contato }\end{array}$ & $\begin{array}{l}\text { A incorporação de nanodiamantes nas resinas } \\
\text { acrílicas diminuiu a adesão de Candida } \\
\text { albicans e a rugosidade da superfície, } \\
\text { principalmente na concentração de } 1 \% \text {. Não } \\
\text { houve nenhum efeito no ângulo de contato. } \\
\text { Logo, é um método de grande valor na } \\
\text { prevenção de estomatites protéticas. }\end{array}$ \\
\hline
\end{tabular}




\begin{tabular}{|c|c|c|c|c|}
\hline $\begin{array}{l}\text { Nazirkar, } \\
\text { Bhanushali, } \\
\text { Singh, } \\
\text { Pattanaik, } \\
\& \quad \text { Raj } \\
(2014)\end{array}$ & Termopolimerizável & $\begin{array}{l}\text { Inclusão de nanopartículas } \\
\text { de dióxido de titânio a } 0,5 \% \\
\text { e } 1 \% \text {. } \\
\mathbf{n}=\mathbf{1 5} \text { por grupo }\end{array}$ & $\begin{array}{l}\text { Resistência } \\
\text { flexural }\end{array}$ & $\begin{array}{l}\text { A inclusão de nanopartículas (NP) de dióxido } \\
\text { de titânio nas resinas acrílicas pode afetar a } \\
\text { resistência à flexão, devido à possibilidade dos } \\
\text { aditivos das NPs elevarem a quantidade de } \\
\text { monômero residual não reagido, diminuindo a } \\
\text { resistência do material. }\end{array}$ \\
\hline $\begin{array}{l}\text { Tsutsumi- } \\
\text { Arai et al. } \\
(2019)\end{array}$ & Termopolimerizável & $\begin{array}{l}\text { Imersão em extrato de } \\
\text { semente de toranja a } 0,1 \% \text { e } \\
1 \% \text {, solução de Polident e } \\
\text { solução de Polident + } \\
\text { extrato de semente de } \\
\text { toranja } 0,1 \% \text {. } \\
\mathbf{n}=\mathbf{5 0} \text { por grupo }\end{array}$ & $\begin{array}{l}\text { Potencial } \\
\text { antimicrobiano, } \\
\text { rugosidade } \\
\text { superficial, } \\
\text { dureza } \\
\text { superficial, } \\
\text { resistência e } \\
\text { módulo flexural }\end{array}$ & $\begin{array}{l}\text { A imersão na solução do extrato da semente de } \\
\text { toranja (EST) a } 1 \% \text { por } 5 \text { min eliminou quase } \\
\text { completamente o biofilme de } C \text {. albicans. A } \\
\text { concentração de EST a } 0,1 \% \text {, Polident e EST } \\
0,1 \% \text { associado ao Polident mostrou um efeito } \\
\text { inibitório significativo do biofilme. Nenhuma } \\
\text { mudança significativa na superfície, resistência } \\
\text { ou módulo flexural foi observada após a } \\
\text { imersão em qualquer uma das soluções. }\end{array}$ \\
\hline $\begin{array}{l}\text { Yadav, } \\
\text { Saraf, } \\
\text { Mishra, \& } \\
\text { Hazari } \\
(2015)\end{array}$ & Termopolimerizável & $\begin{array}{l}\text { Inclusão de gluconato de } \\
\text { clorexidina, fluconazol e } \\
\text { zeólito de prata e zinco na } \\
\text { resina acrílica. } \\
\mathbf{n = 1 0} \text { por grupo }\end{array}$ & $\begin{array}{l}\text { Resistência } \\
\text { flexural }\end{array}$ & $\begin{array}{l}\text { A inclusão dos materiais nas resinas acrílicas à } \\
\text { base de PMMA promovem uma diminuição } \\
\text { significativa na resistência flexural da resina. }\end{array}$ \\
\hline $\begin{array}{l}\text { Nirale, } \\
\text { Thombre, } \\
\text { \& Kubasad } \\
(2012)\end{array}$ & $\begin{array}{l}\text { Termopolimerizável e } \\
\text { autopolimerizável }\end{array}$ & $\begin{array}{l}\text { Imersão em hipoclorito de } \\
\text { sódio } 0,525 \% \quad \mathrm{e} \\
\text { aquecimento em energia de } \\
\text { micro-ondas } 650 \mathrm{~W} . \\
\mathbf{n = 2 0} \text { por grupo }\end{array}$ & $\begin{array}{l}\text { Estabilidade } \\
\text { dimensional }\end{array}$ & $\begin{array}{l}\text { A desinfecção por micro-ondas promoveu } \\
\text { redução dimensional em ambas as resinas } \\
\text { acrílicas. A desinfecção química com } \\
\text { hipoclorito de sódio não causou alterações } \\
\text { significativas em ambas as resinas. }\end{array}$ \\
\hline $\begin{array}{l}\text { Liu et al. } \\
\text { (2017) }\end{array}$ & Termopolimerizável & $\begin{array}{l}\text { Revestimento de plasma de } \\
\text { trimetilsilano na resina } \\
\text { acrílica. } \\
\mathbf{n = 1 5} \text { por grupo }\end{array}$ & $\begin{array}{l}\text { Potencial } \\
\text { antimicrobiano } \\
\text { Ângulo de } \\
\text { contato }\end{array}$ & $\begin{array}{l}\text { O alto ângulo de contato com a água ou } \\
\text { hidrofobia da resina acrílica foi elevado após o } \\
\text { revestimento. A adesão de biofilme de } C \text {. } \\
\text { albicans foi reduzido de forma significativa nas } \\
\text { superfícies lisas e rugosas das amostras que } \\
\text { receberam o revestimento. }\end{array}$ \\
\hline $\begin{array}{l}\text { Sharma, } \\
\text { Garg, \& } \\
\text { Kalra, } \\
(2017)\end{array}$ & Termopolimerizável & $\begin{array}{l}\text { Imersão em hipoclorito de } \\
\text { sódio a } 1 \%, \text { solução de } \\
\text { Fittydent } \quad \text { (Fittydent) } \\
\text { vinagre. } \\
\text { n=8 por grupo }\end{array}$ & $\begin{array}{l}\text { Rugosidade } \\
\text { superficial } \\
\text { resistência } \\
\text { flexural }\end{array}$ & $\begin{array}{l}\text { A imersão em hipoclorito de sódio a } 1 \% \text { por } \\
\text { três meses promoveu redução significativa na } \\
\text { resistência flexural e aumento de rugosidade de } \\
\text { superfície, em comparação à imersão em } \\
\text { vinagre e pastilhas Fittydent. Pastilhas Fittydent } \\
\text { e vinagre podem ser recomendados como um } \\
\text { agente de limpeza química para uso rotineiro a } \\
\text { longo prazo. }\end{array}$ \\
\hline $\begin{array}{l}\text { Porwal, } \\
\text { Khandelwal } \\
\text { Punia, \& } \\
\text { Sharma } \\
\text { (2017) }\end{array}$ & $\begin{array}{l}\text { Termopolimerizável } \\
\text { convencional, } \\
\text { termopolimerizável de } \\
\text { alto impacto e } \\
\text { poliamida }\end{array}$ & $\begin{array}{l}\text { Imersão em hipoclorito de } \\
\text { sódio a } 0,5 \% \text { e perborato de } \\
\text { sódio } 3,8 \% \text {. } \\
\mathbf{n = 1 0} \text { por grupo }\end{array}$ & $\begin{array}{l}\text { Rugosidade } \\
\text { superficial, } \\
\text { estabilidade de } \\
\text { cor e dureza } \\
\text { superficial }\end{array}$ & $\begin{array}{l}\text { A imersão por } 180 \text { dias nas duas soluções } \\
\text { promoveu alterações de cor em todas as resinas, } \\
\text { em especial a resina de poliamida. Porém essas } \\
\text { mudanças estavam dentro da faixa clinicamente } \\
\text { aceita para estabilidade de cor. A alteração de } \\
\text { dureza superficial da resina termopolimerizável } \\
\text { convencional foi maior do que as outras resinas. } \\
\text { Todas as resinas acrílicas testadas exibiram } \\
\text { alteração de cor, dureza superficial e } \\
\text { rugosidade da superfície em algum grau em } \\
\text { ambas as soluções desinfetantes. }\end{array}$ \\
\hline $\begin{array}{l}\text { Wen, Jiang, } \\
\text { Yeh, \& Sun } \\
(2016)\end{array}$ & $\begin{array}{l}\text { Termopolimerizável de } \\
\text { alto impacto }\end{array}$ & $\begin{array}{l}\text { Inclusão de poli (1-vinil-2- } \\
\text { pirrolidona) - PNVP*, de } \\
\text { poli (ácido metacrílico) - } \\
\text { PMAA e de poli (2- } \\
\text { hidroxietil metacrilato) - } \\
\text { PHEMA*. } \\
\text { *os polímeros foram } \\
\text { incluídos com } \\
\text { polimerização iniciada por } \\
\text { plasma; em seguida foi } \\
\text { avaliada a capacidade de } \\
\text { ligação destes ao } \\
\text { miconazol. } \\
\text { n= não informado }\end{array}$ & $\begin{array}{l}\text { Potencial } \\
\text { antimicrobiano }\end{array}$ & $\begin{array}{l}\text { Os grupos experimentais apresentaram aumento } \\
\text { da capacidade de ligação ao miconazol, se } \\
\text { comparados aos grupos controle que não } \\
\text { receberam a inclusão, promovendo uma } \\
\text { liberação sustentada da droga e potentes efeitos } \\
\text { de controle de biofilme de C. albicans. }\end{array}$ \\
\hline Kamonkhan & ermopolimerizável & Incorporação & Potencial & A resina acrílica que recebeu incorp \\
\hline
\end{tabular}




\begin{tabular}{|c|c|c|c|c|}
\hline $\begin{array}{l}\text { tikul, } \\
\text { Arksornnuk } \\
\text { it, \& } \\
\text { Takahashi } \\
\text { (2017) }\end{array}$ & & $\begin{array}{l}\text { nanopartículas de óxido de } \\
\text { zinco (ZnOnps) a } 1,25 \%, \\
2,5 \% \text { e } 5 \% \text { com/sem } \\
\text { modificação r de } \\
\text { metacriloxipropiltrimetoxisi } \\
\text { lano. } \\
\text { n=8 por grupo }\end{array}$ & $\begin{array}{l}\text { antimicrobiano, } \\
\text { estabilidade de } \\
\text { cor e opacidade, } \\
\text { resistência } \\
\text { flexural e } \\
\text { módulo flexural }\end{array}$ & $\begin{array}{l}\text { ZnOnps silanizado, em especial a concentração } \\
\text { de } 2,5 \% \text {, teve maior efeito antifúngico, menor } \\
\text { diferença de cor e opacidade em comparação às } \\
\text { resinas que receberam incorporação de ZnOnps } \\
\text { não silanizados, também mantendo as suas } \\
\text { propriedades mecânicas de resistência e módulo } \\
\text { flexural. }\end{array}$ \\
\hline $\begin{array}{l}\text { Sookto, } \\
\text { Srithavaj, } \\
\text { Thaweboon } \\
\text { Thaweboon } \\
\text { Shrestha \& } \\
\text { (2013) }\end{array}$ & $\mathrm{el}$ & $\begin{array}{l}\text { Imersão no óleo essencial } \\
\text { de Salvia officinalis L. } \\
\text { (sálvia) nas concentrações } \\
\text { de } 1 \% \text {, } 0,5 \% \text { e } 0,25 \% \text {, e } \\
\text { clorexidina a } 0,2 \% \text {. } \\
\text { n = não especifica } \\
\text { quantidade }\end{array}$ & $\begin{array}{l}\text { Potencial } \\
\text { antimicrobiano }\end{array}$ & $\begin{array}{l}\text { O óleo essencial de Salvia officinalis L. } \\
\text { promoveu excelente atividade antimicrobiana } \\
\text { contra C. albicans, assim como teve efeitos } \\
\text { inibitórios na adesão das células na superfície } \\
\text { da resina acrílica. Houve redução de } 89 \% \text { - } \\
96 \% \text { na adesão de C. albicans com a imersão } \\
\text { do óleo de Salvia officinalis L. a } 1 \% \text {, enquanto } \\
\text { a clorexidina a } 0,2 \% \text { mostrou uma redução de } \\
96 \%-98 \% \text {. }\end{array}$ \\
\hline $\begin{array}{l}\text { Tripathi, } \\
\text { Phukela, } \\
\text { Yadav, \& } \\
\text { Malhotra } \\
\text { (2018) }\end{array}$ & $\begin{array}{l}\text { Termoplástica com } \\
\text { amostras preparadas por } \\
\text { injeção a vácuo ou } \\
\text { prensadas. }\end{array}$ & $\begin{array}{l}\text { Imersão em saliva artificial, } \\
\text { solução de Fittydent } \\
\text { (Fittydent) e solução de } \\
\text { Clinsodent (ICPA Health } \\
\text { Products Ltda.). } \\
\text { n= } 40 \text { por grupo }\end{array}$ & $\begin{array}{l}\text { Rugosidade } \\
\text { superficial }\end{array}$ & $\begin{array}{l}\text { A imersão das amostras em Fittydent e } \\
\text { Clinsodent, aumentou a rugosidade de } \\
\text { superfície nas amostras de resina injetadas, em } \\
\text { comparação com as prensadas, que não } \\
\text { apresentaram qualquer alteração de superfície } \\
\text { nos intervalos de tempo de } 0-45 \text { dias. }\end{array}$ \\
\hline
\end{tabular}

Fonte: Autores.

Quadro 2 - Características dos estudos clínicos e clínico-laboratoriais incluídos.

\begin{tabular}{|c|c|c|c|c|}
\hline Autor/ano & $\begin{array}{l}\text { Tipo de resina } \\
\text { acrílica }\end{array}$ & Tipo de desinfecção & $\begin{array}{l}\text { Testes } \\
\text { realizados }\end{array}$ & Resultados \\
\hline $\begin{array}{l}\text { Salles et al. } \\
(2015) *\end{array}$ & $\begin{array}{l}\text { Termopolimerizáv } \\
\text { el }\end{array}$ & $\begin{array}{l}\text { Imersão e escovação da prótese } \\
\text { em hipoclorito de sódio } 0,25 \% \text { e } \\
0,5 \% \text {, e em Óleo de Ricinus } \\
\text { communis (mamona) } 10 \% . \\
\mathbf{n = 6 4} \text { por grupo }\end{array}$ & $\begin{array}{l}\text { Potencial } \\
\text { antimicrobiano }\end{array}$ & $\begin{array}{l}\text { O hipoclorito de sódio a } 0,5 \% \text { teve uma elevada } \\
\text { eficiência no controle microbiano, enquanto as } \\
\text { demais soluções apresentaram atividade } \\
\text { moderada contra C. albicans. }\end{array}$ \\
\hline $\begin{array}{l}\text { Badaró et } \\
\text { al. }(2017) *\end{array}$ & $\begin{array}{l}\text { Termopolimerizáv } \\
\text { el }\end{array}$ & $\begin{array}{l}\text { Imersão e escovação da prótese } \\
\text { em hipoclorito de sódio a } 0,25 \% \\
\text { e } 0,5 \% \text { e em solução de Ricinus } \\
\text { communis (mamona) a } 10 \% \text {. } \\
\mathbf{n = 8}\end{array}$ & $\begin{array}{l}\text { Potencial } \\
\text { antimicrobiano } \\
\text { e satisfação do } \\
\text { paciente }\end{array}$ & $\begin{array}{l}\text { As soluçães testadas promoveram considerável } \\
\text { remoção do biofilme, redução na formação de } \\
\text { colônias microbianas na superfície das próteses, } \\
\text { remissão da candidíase e foram aprovadas pelos } \\
\text { pacientes. Logo, a solução de Ricinus communis a } \\
10 \% \text { e Hipoclorito de sódio } 0,25 \% \text { podem ser } \\
\text { indicados como soluções desinfetantes para } \\
\text { usuários de próteses. }\end{array}$ \\
\hline $\begin{array}{l}\text { Aoun, } \\
\text { Nasseh, } \\
\text { Saadeh, } \\
\text { Cassia, \& } \\
\text { Berberi } \\
(2015) *\end{array}$ & $\begin{array}{l}\text { Não informado; os } \\
\text { autores relatam o } \\
\text { uso de próteses de } \\
\text { pacientes. }\end{array}$ & $\begin{array}{l}\text { Imersão em Hexetidina a } 0,1 \% \text {. } \\
\mathbf{n}=\mathbf{2 0} \text { por grupo }\end{array}$ & $\begin{array}{l}\text { Potencial } \\
\text { antimicrobiano }\end{array}$ & $\begin{array}{l}\text { A solução de Hexetidina a } 0,1 \% \text { apresentou } \\
\text { resultados moderados de redução do biofilme de } \\
\text { C. albicans, após a imersão das próteses por } 8 \\
\text { horas durante } 4 \text { noites consecutivas. }\end{array}$ \\
\hline $\begin{array}{l}\text { Silva } \\
\text { Lovato et } \\
\text { al. }(2010) *\end{array}$ & $\begin{array}{l}\text { Termopolimerizáv } \\
\text { el }\end{array}$ & $\begin{array}{lr}\text { Imersão em } & \text { solução de } \\
\text { NitrAdine }^{\mathrm{TM}} & \text { (Medical } \\
\text { Interporous }^{\mathrm{TM}} \text { ). } & \\
\mathbf{n = 2 0} \text { por grupo } & \\
\end{array}$ & $\begin{array}{l}\text { Potencial } \\
\text { antimicrobiano }\end{array}$ & $\begin{array}{l}\text { As pastilhas à base de NitrAdine }{ }^{\mathrm{TM}} \text { são eficientes } \\
\text { na remoção de biofilme das próteses dentárias, } \\
\text { assim como possuem uma clara ação } \\
\text { antimicrobiana. }\end{array}$ \\
\hline $\begin{array}{l}\text { Oliveira et } \\
\text { al. } \quad(2014) \\
* *\end{array}$ & $\begin{array}{l}\text { Termopolimerizáv } \\
\text { el }\end{array}$ & $\begin{array}{l}\text { Imersão em óleo essencial de } \\
\text { Cinnamomum zeylanicum } \\
\text { (Caneleira-verdadeira), nistatina } \\
\text { e saliva artificial. } \\
\mathbf{n = 1 0} \text { por grupo }\end{array}$ & $\begin{array}{l}\text { Potencial } \\
\text { antimicrobian, } \\
\text { rugosidade } \\
\text { superficial, } \\
\text { dureza } \\
\text { superficial }\end{array}$ & $\begin{array}{l}\text { O óleo essencial de } C \text {. zeylanicum possui } \\
\text { atividade antimicrobiana frente a } C \text {. albicans, } \\
\text { entretanto promove alterações na rugosidade e } \\
\text { dureza da resina acrílica, semelhantes as } \\
\text { observadas nas amostras imersas em saliva } \\
\text { artificial e nistatina. O uso clínico do óleo } \\
\text { propiciou segurança e tolerância satisfatória aos } \\
\text { pacientes. }\end{array}$ \\
\hline $\begin{array}{l}\text { Asnaashari, } \\
\text { Motamedi, } \\
\text { Asnaashari, } \\
\& \quad \text { Azari- } \\
\text { Marhabi } \\
(2019) * *\end{array}$ & $\begin{array}{l}\text { Não informado; os } \\
\text { autores relatam o } \\
\text { uso de próteses de } \\
\text { pacientes. }\end{array}$ & $\begin{array}{l}\text { Aplicação de plasma frio por } 30 \\
\text { e } 60 \text { segundos, e de spray } \\
\text { ASEPTOPRINT (OCC). } \\
\mathbf{n = 1 0} \text { por grupo }\end{array}$ & $\begin{array}{l}\text { Potencial } \\
\text { antimicrobiano }\end{array}$ & $\begin{array}{l}\text { As colônias microbianas foram reduzidas após a } \\
\text { desinfecção em todos os grupos. Entretanto, o } \\
\text { spray ASEPTOPRINT promoveu um efeito mais } \\
\text { significativo em comparação ao plasma frio, que } \\
\text { não apresentou diferenças com tempo de } \\
\text { aplicação. }\end{array}$ \\
\hline
\end{tabular}


*Ensaios clínicos, **Ensaios clínico-laboratoriais. Fonte: Autores.

\section{Discussão}

A estomatite protética (EP) desencadeada por C. albicans representa um processo inflamatório da mucosa na área chapeável da prótese removível, parcial ou total, sendo uma lesão muito comum em pacientes que fazem uso de próteses totais superiores, com uma prevalência de $15 \%$ a $77 \%$ de acometimento (Hashizume et al., 2015; Sookto, Srithavaj, Thaweboon, Thaweboon, \& Shrestha, 2013). Os principais fatores etiológicos da estomatite protética são as microporosidades das resinas, traumas e deficiência de higiene bucal e das próteses - e a associação destes fatores culmina em um ambiente favorável à proliferação de microrganismos e formação de um biofilme patogênico (Aoun, Nasseh, Saadeh, Cassia, \& Berberi, 2015).

A correta higienização bucal e das próteses consiste em um importante fator na prevenção e tratamento da EP (Zoccolotti et al., 2018). Logo, diversos protocolos são instituídos, relacionados aos métodos mecânicos, químicos e à associação destes para controle do biofilme na superfície da prótese, evitando assim o desenvolvimento de processos inflamatórios (Badaró et al., 2017). Aspectos do perfil do paciente, como idade e limitações de habilidades motoras, promovem a necessidade dessa associação para melhor eficácia da manutenção e desinfecção das próteses (Martins \& Moretti Neto, 2017).

Dentre os protocolos de desinfecção, a higienização mecânica por meio da escovação, assim como higienização química por imersão em soluções como HS, digluconato de clorexidina, hexetidina, perborato de sódio, vinagre, dentre outros, são as mais comuns (Castro et al., 2015; Sczepanski et al., 2014; Aoun et al., 2015). Paralelamente, métodos alternativos como a desinfecção pela energia de micro-ondas, por luz ultravioleta, por plasma e a utilização de produtos químicos de limpeza como sabonetes, pastilhas efervescentes e enxaguatórios bucais também vêm sendo utilizados para este fim (Asnaashari, Motamedi, Asnaashari, \& Azari-Marhabi, 2019; Jafari, Tafti, Hoseiny, \& Kazemi, 2015; Zoccolotti et al., 2018; Sharma, Garg, \& Kalra, 2017; Asnaashari, Motamedi, Asnaashari, \& Azari-Marhabi, 2019).

Estudos apontam que os protocolos de desinfecção podem ser controversos, devido à possibilidade de alterar as propriedades do material, como dureza, rugosidade, estabilidade dimensional, cor e propriedades de flexão que em conjunto podem exercer grande influência clínica na longevidade da prótese (Machado, Giampaolo, Vergani, Souza, \& Jorge, 2011; AlSaadi, 2014; Nirale et al., 2012; Tripathi et al., 2018; Asnaashari et al., 2019).

O HS é o agente de desinfecção mais utilizado para desinfetar próteses à base de resina acrílica. ${ }^{[20]}$ Em diversos estudos realizados, o HS promoveu redução ou controle máximo de C. albicans, se mostrando eficaz antimicrobiano em diversas concentrações, em especial a 1\% (Salles et al., 2015; Hashizume et al., 2015; Yildirim-Bicer et al., 2014; Al-Saadi, 2014; Badaró et al., 2017).

Apesar de ser um agente com excelentes propriedades, alguns estudos relataram que todas as resinas acrílicas tratadas com HS exibiram alteração de cor, de dureza superficial, resistência flexural e rugosidade, principalmente quando utilizado em períodos longos (Sharma et al., 2017; Porwal, Khandelwal, Punia, \& Sharma, 2017). Em contrapartida, outros estudos relatam que o HS promove menores danos à estrutura da resina, sendo clinicamente alterações insignificantes, principalmente quanto à estabilidade dimensional, dureza e estabilidade de cor (Martins \& Moretti Neto, 2017; Sczepanski et al., 2014; Al-Saadi, 2014; Nirale et al., 2012).

A clorexidina é um desinfetante químico capaz de reduzir as colônias de $C$. albicans aderidas à resina acrílica (Hashizume et al., 2015; Sookto et al., 2013). Adicionalmente, a clorexidina a 0,12\% promove mais danos à estrutura da prótese, principalmente no tocante à redução da microdureza de superfície, se comparada à imersão em HS a $1 \%$ (Martins \& Moretti Neto, 2017).

A desinfecção com vinagre, seja de álcool ou branco, promove um efeito fungicida sob as cepas de C. albicans, sendo 
considerado uma alternativa viável e de baixo custo para os pacientes, sem causar alteração na cor, na rugosidade e na resistência flexural das próteses (Hashizume et al., 2015; Yildirim-Bicer et al., 2014; Castro et al., 2015; Sharma et al., 2017). O peróxido de hidrogênio $10 \mathrm{v}$, a solução de Hexetidina a $0,1 \%$ promovem um efeito moderado na redução do biofilme de $C$. albicans (Salles et al., 2015; Hashizume et al., 2015; Aoun et al., 2015).

Pastilhas e sabonetes higienizadores antissépticos podem ser utilizados para desinfecção, principalmente levando em consideração que são encontrados facilmente em pontos comerciais. Esses materiais químicos podem ser usados como agente de limpeza para uso rotineiro, visto que são eficientes na remoção de biofilme das próteses dentárias (Zoccolotti et al., 2018; Sharma et al., 2017; Tripathi et al., 2018; Silva-Lovato et al., 2010). Entretanto, o estudo realizado por Al-Saadi (2014) identificou que pastilhas e sabonetes higienizadores não atingiram uma redução fúngica eficiente, e Martins \& Moretti Neto (2017) identificaram que a imersão da resina acrílica na solução de Corega Tabs (GSK) promove uma redução da microdureza superficial.

$\mathrm{O}$ aquecimento em micro-ondas para desinfecção em diversas potências promove uma excelente redução fúngica de próteses dentárias (Fortes et al., 2015; Yildirim-Bicer et al., 2014; Al-Saadi, 2014). Entretanto, essa alternativa de desinfecção pode promover alterações físicas significativas nas resinas acrílicas, principalmente dimensionais, com redução de volume no aquecimento em condições de umidade (Machado et al., 2011; Polychronakis, Yannikakis, \& Zissis, 2014; Nirale et al., 2012). No estudo realizado por Fortes et al. (2015) o ácido peracético a 0,2\% tem efeito similar à desinfecção por micro-ondas 840 W.

O plasma frio é uma alternativa de desinfecção que reduz significativamente as colônias microbianas das próteses, assim como o plasma de trimetilsilano usado como revestimento pode reduzir a adesão fúngica (Asnaashari et al., 2019; Liu et al., 2017). Entretanto, no estudo realizado por Asnaashari et al. (2019), o spray ASEPTOPRINT para desinfecção promoveu um efeito mais significativo quando comparado ao plasma frio.

Métodos alternativos como substâncias fitoterápicas com atividade antimicrobiana têm sido alvo de estudos também, em função do seu potencial para prevenção de doenças bucais, especialmente os que se relacionam ao biofilme oral (Jafari et al., 2015; Madeira et al., 2016; Sookto et al., 2013; Oliveira et al., 2014).

Em um estudo realizado por Badaró et al. (2017), a solução de Ricinus communis a 10\% promoveu a remissão da candidíase de pacientes, sendo indicada como solução desinfetante para os usuários de próteses. Extratos de Zataria multiflora, Salvia officinalis, Nigella sativa e semente de toranja possuem potencial antimicrobiano para promover a redução de $C$. albicans das superfícies de resinas acrílicas, sem propiciar alterações significativas no material (Ariamanesh et al., 2019; Jafari et al., 2015; Tsutsumi-Arai et al., 2019; Sookto et al., 2013). Todavia, um estudo realizado com extrato de Cinnamomum zeylanicum comprovando sua atividade antimicrobiana, promoveu alterações na rugosidade e dureza da resina acrílica (Oliveira et al., 2014).

A incorporação de agentes antimicrobianos na resina acrílica tem se tornado uma tendência dos materiais dentários, com o intuito de induzir propriedades antimicrobianas capazes de prevenir a adesão de patógenos (Fouda et al., 2019; Nazirkar, Bhanushali, Singh, Pattanaik, \& Raj, 2014). A inclusão de materiais bioativos como digluconato de clorexidina e fluconazol, ou mesmo de nanomateriais em resinas acrílicas, como nanodiamante, vanadato de prata nanoestruturado, nanopartículas de dióxido de titânio e de óxido de zinco promovem um efeito antifúngico significativo, diminuindo a adesão de C. albicans sob as superfícies das resinas acrílicas (Castro et al., 2014; Maluf et al., 2020; Fouda et al., 2019; Nazirkar et al., 2014; Kamonkhantikul et al., 2017; Tripathi et al., 2018). Assim como a inclusão de polímeros a fim de melhorar a capacidade de ligação dos fármacos com a superfície da prótese, potencializando o efeito do tratamento antifúngico (Wen, Jiang, Yeh, \& Sun, 2016).

Por outro lado, a incorporação destes materiais pode alterar as propriedades físicas da resina acrílica, como a 
resistência flexural do material, cor e estabilidade dimensional ou, de forma contrária, aumentar a sua dureza superficial e a capacidade de resistência à compressão (Yadav et al., 2015; Nazirkar et al., 2014; Castro et al., 2014; Kamonkhantikul et al., 2017).

Logo, para evitar efeitos deletérios, a incorporação de aditivos antimicrobianos deve ser avaliada e estudada cuidadosamente, a fim de promover um efeito satisfatório sem alterar as propriedades mecânicas da resina acrílica, tornando-se um grande agente na prevenção de estomatites protéticas (Fouda et al., 2019).

\section{Conclusão}

A maioria dos estudos incluídos nesta revisão integrativa conclui que as técnicas de desinfecção são essenciais para a longevidade das próteses, no tratamento e prevenção da estomatite protética. Diversas opções de materiais e métodos de desinfecção estão disponíveis, entretanto, alguns métodos de desinfecção podem produzir mudanças significativas na estrutura das próteses. Logo, é viável buscar estratégias que demonstrem resultados satisfatórios no controle preventivo ou redução microbiana, seja pela utilização de fitoterápicos ou nanomateriais para inclusão na resina acrílica.

Os estudos que compuseram esta revisão possuem variáveis diferentes entre si, como tamanho dos grupos experimentais, metodologia de ensaio, tipo de descontaminação, o que dificulta o estabelecimento comparativo de forma mais rigorosa entre eles. Estudos futuros são considerados, no tocante à avaliação da desinfecção de próteses parciais removíveis e os seus efeitos sobre as ligas metálicas que compõem essas próteses.

\section{Referências}

Al-Saadi, M. H. (2014). Effectiveness of Chemical and Microwave Disinfection on Denture Biofilm Fungi and the Influence of Disinfection on Denture Base Adaptation. Journal of Indian Prosthodontic Society, 14(1), 24-30.

Aoun, G., Nasseh, I., Saadeh, M., Cassia, A., \& Berberi, A. (2015). Effectiveness of Hexetidine 0.1\% in Eliminating Candida albicans Colonizing Dentures: A Randomized Clinical In Vivo Study. Journal of International Oral Health, 7(1), 1-4.

Ariamanesh, H., Tamizi, N., Yazdinezhad, A., Salah, S., Motamed, N., \& Amanloo, S. (2019). The Effectiveness of Nigella Sativa Alcoholic Extract on the Inhibition of Candida Albicans Colonization and Formation of Plaque on Acrylic Denture Plates: an In Vitro Study. Journal of Dentistry, $20(3), 171-177$.

Asnaashari, M., Motamedi, S., Asnaashari, N., \& Azari-Marhabi, S. (2019). Antimicrobial Activity of Cold Plasma Treatment on Acrylic Denture Bases: An In Vitro Evaluation. Journal of Lasers in Medical Sciences, 10(Suppl 1), S13-S17.

Badaró, M. M., Salles, M. M., Leite, V. M. F., Arruda, C. N. F., Oliveira, V. C., Nascimento, C., Souza, R. F., Paranhos, H. F. O., \& Silva-Lovato, C. H. (2017). Clinical trial for evaluation of Ricinus communis and sodium hypochlorite as denture cleanser. Journal of Applied Oral Science, 25 (3), $324-334$.

Barbosa, D. G. O, Montenegro, A. C., \& Duarte, J. L. P. (2013). Avaliação da rugosidade superficial de três resinas acrílicas para restauração provisória submetidas a diferentes métodos de polimento. Revista Brasileira de Odontologia, 70(2), 152-155.

Bastos, P. L., Mesquita, T. C., Ottoboni, G. S., \& Figueiredo, V. M. G. (2015). Métodos de higienização em próteses dentais removíveis. Revista Bahiana de Odontologia, 6(2), 129-137.

Batista, M. J., Lawrence, H. P., \& Sousa M. L. R. (2015). Classificação das perdas dentárias: fatores associados a uma nova medida em uma população de adultos. Ciência \& Saúde Coletiva, 20(9), 2825-2835.

Batista, M. J., Lawrence, H. P., \& Sousa M. L. R. (2017). Uso e necessidade de prótese dentária em idosos brasileiros segundo a Pesquisa Nacional de Saúde Bucal (SBBrasil 2010): prevalências e fatores associados. Cadernos de Saúde Pública, 33(8), 1-12.

Camacho, D. P., Svidzinski, T. I. E., Furlaneto, M. C., Lopes, M. B \& Correa, G. O. (2014) Resinas acrílicas de uso odontológico à base de polimetilmetacrilato. Brazilian Journal of Surgery and Clinical Research, 6(3), 63-72.

Castro, D. T., Holtz, R. D., Alves, O. L., Watanabe, E., Valente, M. L. C., Silva, C. H. L., \& Reis, A. C. (2014). Development of a novel resin with antimicrobial properties for dental application. Journal of Applied Oral Science, 22(5), 442-449.

Castro, R. D., Mota, A. C. L. G., Lima, E. O., Batista, A. U. D., Oliveira, J. A., \& Cavalcanti, A. L. (2015). Use of alcohol vinegar in the inhibition of Candida spp. and its effect on the physical properties of acrylic resins. BMC Oral Health, 15, 52.

Fernandes, F. H. C. N. (2009). Avaliação da alteração de cor e rugosidade média superficial de resinas acrílicas usadas em bases de próteses após imersão em desinfetantes químicos e bebidas (Dissertação de mestrado). Faculdade de Odontologia de Ribeirão Preto da Universidade de São Paulo, Ribeirão Preto, SP, Brasil. 
Fortes, C. B. B., Leitune, V. C. B., Collares, F. M., Dornelles Junior, N. B., Rodrigues, S. B., \& Samuel, S. W. (2015). Acrylic resin disinfection by peracetic acid and microwave energy. Revista Gaúcha de Odontologia, 63(3), 315-318.

Fouda, S. M., Gad, M. M., Ellakany, P., Al-Thobity, A. M., Al-Harbi, F. A., Virtanen, J. I., \& Raustia, A. (2019). The effect of nanodiamonds on candida albicans adhesion and surface characteristics of PMMA denture base material - an in vitro study. Journal of Applied Oral Science, 27, e20180779.

Hashizume, L. N., Hoscharuk, M. F., \& Moreira, M. J. S. (2015). Effect of affordable disinfectant solutions on Candida albicans adhered to acrylic resin for dental prosthesis. Revista Gaúcha de Odontologia, 63(3), 309-314.

Jafari, A. A., Tafti, A. F., Hoseiny, S. M., \& Kazemi, A. (2015). Antifungal Effect of Zataria multiflora Essence on Experimentally Contaminated Acryl Resin Plates with Candida albicans. Iranian Red Crescent Medical Journal, 17(1), 1-5.

Kamonkhantikul, K., Arksornnukit, M., \& Takahashi, H. (2017). Antifungal, optical, and mechanical properties of polymethylmethacrylate material incorporated with silanized zinc oxide nanoparticles. International Journal of Nanomedicine, 12, 2353-2360.

Leite, D. P., Piva, M. R., \& Martins Filho, P. R. S. (2015). Identificação das espécies de Candida em portadores de estomatite protética e avaliação da susceptibilidade ao miconazol e à terapia fotodinâmica. Revista de Odontologia da UNESP, 44(1), 12-17.

Sesma, N. \& Morimoto, S. (2014) Estomatite protética: etiologia, tratamento e aspectos clínicos. Journal of Biodentistry and Biomaterials, 1(2), 24-29.

Liu, T., Xu, C., Hong, L., Garcia-Godoy, F., Hottel, T., Babu, J., \& Yu, Q. (2017). Effects of trimethylsilane (TMS) plasma coating on the hydrophobicity of denture base resin and adhesion of C. albicans on resin surfaces. Journal of Prosthetic Dentistry, 118(6), 765-770.

Machado, A. L., Giampaolo, E. T., Vergani, C. E., Souza, J. F., \& Jorge, J. H. (2011). Changes in roughness of denture base and reline materials by chemical disinfection or microwave irradiation. Surface roughness of denture base and reline materials. Journal of Applied Oral Science, 19(5), 521-528.

Madeira, P. L. B., Carvalho, L. T., Paschoal, M. A. B., Sousa, E. M., Moffa, E. B., Silva, M. A. S., Tavarez, R. J. R., \& Gonçalves. L. M. (2016). In vitro Effects of Lemongrass Extract on Candida albicans Biofilms, Human Cells Viability, and Denture Surface. Frontiers in Cellular and Infection Microbiology, 6,71

Maluf, C. V., Peroni, L. V., Menezes, L. R., Coutinho, W., Lourenço, E. J. V., \& Telles, D. M. (2020). Evaluation of the physical and antifungal effects of chlorhexidine diacetate incorporated into polymethyl methacrylate. Journal of Applied Oral Science, 28, e20190039.

Martins, E. G., \& Moretti Neto, R. T. (2017). Effect of repeated cycles of chemical disinfection in microhardness of acrylic resins of complete denture base. Revista Gaúcha de Odontologia, 65(3), 196-201.

Nazirkar, G., Bhanushali, S., Singh, S., Pattanaik, B., \& Raj, N. (2014). Effect of Anatase Titanium Dioxide Nanoparticles on the Flexural Strength of Heat Cured Poly Methyl Methacrylate Resins: An In-Vitro Study. Journal of Indian Prosthodontic Society, 14(1), 144-149.

Nirale, R. M., Thombre, R., \& Kubasad, G. (2012). Comparative evaluation of sodium hypochlorite and microwave disinfection on dimensional stability of denture bases. Journal of Advanced Prosthodontics, 4(1), $24-29$.

Oliveira, J. A., Silva, I. C. G., Trindade, L. A., Lima, E. O., Carlo, H. L., Cavalcanti, A. L., \& Castro, R. D. (2014). Safety and Tolerability of Essential Oil from Cinnamomum zeylanicum Blume Leaves with Action on Oral Candidosis and Its Effect on the Physical Properties of the Acrylic Resin. Evidence-based Complementary and Alternative Medicine, 2014, 325670.

Polychronakis, N., Yannikakis, S., \& Zissis, A. (2014). The Effect of Repeated Microwaving Disinfection on the Dimensional Stability of Acrylic Dentures. Acta stomatologica Croatica, 48(4), 279-284.

Porwal, A., Khandelwal, M., Punia, V., \& Sharma, V. (2017). Effect of denture cleansers on color stability, surface roughness, and hardness of different denture base resins. Journal of Indian Prosthodontic Society, 17(1), 61-67.

Salles, M. M., Badaró, M. M., Arruda, C. N. F., Leite, V. N. F., Silva, C. H. L., Watanabe, E., Oliveira, V. C., \& Paranhos, H. F. O. (2015). Antimicrobial activity of complete denture cleanser solutions based on sodium hypochlorite and Ricinus communis - a randomized clinical study. Journal of Applied Oral Science, 23(6), 637-642.

Sczepanski, F., Sczepanski, C. R. B., Berger, S. B., Consani, R. L. X., Gonini Júnior, A., \& Guiraldo, R. D. (2014). Effect of sodium hypochlorite and peracetic acid on the surface roughness of acrylic resin polymerized by heated water for short and long cycles. European Journal of Dentistry, 8(4), 533-537.

Sharma, P., Garg, S., \& Kalra, N. M. (2017). Effect of Denture Cleansers on Surface Roughness and Flexural Strength of Heat Cure Denture Base Resin-An In vitro Study. Journal of Clinical and Diagnostic Research, 11(8), ZC94-ZC97.

Silva-Lovato, C. H., Wever, B., Adriaens, E., Paranhos, H. F. O., Watanabe, E., Pisani, M. X., Souza, R. F., \& Ito, I. Y. (2010). Clinical and antimicrobial efficacy of NitrAdineTM-based disinfecting cleaning tablets in complete denture wearers. Journal of Applied Oral Science, 18(6), 560-565.

Simões, R. J., Fonseca, P., \& Figueiral, M. H. (2013). Infecções por Candida spp. na Cavidade Oral. Odontologia Clínico-Científica, 12(1), 19-22.

Sookto, T., Srithavaj, T., Thaweboon, S., Thaweboon, B., \& Shrestha, B. (2013). In vitro effects of Salvia officinalis L. essential oil on Candida albicans. Asian Pacific Journal of Tropical Biomedicine, 3(5), 376-380.

Sugio, C. Y. C., Garcia, A. A. M. N., Albach, T., Moraes, G. S., Bonfante, E. A., Urban, V. M., Neppelenbroek, K. H. (2020). Candida-Associated Denture Stomatitis and Murine Models: What Is the Importance and Scientific Evidence? Journal of Fungi, 6(2), 70.

Tripathi, P., Phukela, S. S., Yadav, B., \& Malhotra, P. (2018). An in vitro study to evaluate and compare the surface roughness in heat-cured denture-based resin and injection-molded resin system as affected by two commercially available denture cleansers. Journal of Indian Prosthodontic Society, 18(4), 291-298. 
Research, Society and Development, v. 10, n. 7, e17210716381, 2021

(CC BY 4.0) | ISSN 2525-3409 | DOI: http://dx.doi.org/10.33448/rsd-v10i7.16381

Tsutsumi-Arai, C., Takakusaki, K, Arai, Y., Terada-Ito, C., Takebe, Y., Imamura, T., Ide, S., Tatehara, S., Tokuyama-Toda, R., Wakabayashi, N., \& Satomura, K. (2019). Grapefruit seed extract effectively inhibits the Candida albicans biofilms development on polymethyl methacrylate denture-base resin. PLoS One. 14(5), 1-13.

Wen, J., Jiang, F., Yeh, C., \& Sun, Y. (2016). Controlling Fungal Biofilms with Functional Drug Delivery Denture Biomaterials. Colloids and Surfaces B: Biointerfaces, 140, 19-27.

Yadav, N. S., Saraf, S., Mishra, S. K., \& Hazari, P. (2015). Effects of fluconazole, chlorhexidine gluconate, and silver-zinc zeolite on flexural strength of heatcured polymethyl methacrylate resin. Journal of Natural Science, Biology and Medicine, 6(2), 340-342.

Yildirim-Bicer, A. Z., Peker, I., Akca, G., \& Celik I. (2014). In Vitro Antifungal Evaluation of Seven Different Disinfectants on Acrylic Resins. BioMed Research International, 2014, 519098

Zoccolotti, J. O., Tasso, C. O., Arbeláez, M. I. A., Malavolta, I. F., Pereira, E. C. S., \& Esteves, C. S. G. (2018). Properties of an acrylic resin after immersion in antiseptic soaps: Low-cost, easy-access procedure for the prevention of denture stomatitis. PLoS One, 13(8), 1-22. 